\title{
Efeitos fitotóxicos do fluoreto na morfoanatomia foliar de Brachiaria brizantha (Hochst. ex A. Rich.) Stapf e Brachiaria decumbens Stapf (Poaceae)
}

\author{
Alice Pita-Barbosa ${ }^{1}$, Bruno Francisco Sant'Anna-Santos ${ }^{1,2}$, Kellen Lagares Ferreira Silva ${ }^{1}$, \\ Aristéa Alves Azevedo ${ }^{1}$ e Diego Ismael Rocha ${ }^{1}$
}

Recebido em 29/05/2008. Aceito em 18/02/2009

RESUMO - (Efeitos fitotóxicos do fluoreto na morfoanatomia foliar de Brachiaria brizantha (Hochst. Ex A. Rich.) Stapf e Brachiaria decumbens Stapf (Poaceae)). Visando avaliar os efeitos do fluoreto sobre capim-braquiária, plantas de Brachiaria brizantha e B. decumbens foram submetidas a nevoeiros simulados com fluoreto $\left(10 \mu \mathrm{g} \mathrm{ml}^{-1}\right)$. Amostras foliares de porções aparentemente sadias foram coletadas 24 horas após a última exposição para análises microscópicas. Folhas, raízes e rizomas foram submetidos à quantificação do teor de fluoreto. As folhas apresentaram necroses pequenas e esparsas. Somente as folhas acumularam fluoreto, apresentando teores 4,4 e 5,2 vezes maiores que no tratamento controle, em $B$. brizantha e $B$. decumbens, respectivamente, não havendo diferença no potencial acumulador das duas espécies. As principais alterações micromorfológicas observadas foram lesões próximas aos tricomas, sugerindo que estes sejam as vias preferenciais de entrada do poluente nas plantas. Porções foliares, visualmente sadias, de ambas as espécies apresentaram danos microscópicos antes do surgimento de sintomas, havendo perda da turgidez das células buliformes em $B$. brizantha e de todos os tecidos em $B$. decumbens. Alterações micromorfométricas foram observadas somente em $B$. decumbens, indicando sua maior sensibilidade ao fluoreto, em comparação com $B$. brizantha. A realização de experimentos de longa duração será fundamental para elucidar o potencial bioacumulador de $B$. brizantha. Palavras-chave: anatomia vegetal, capim-braquiária, necrose

ABSTRACT - (Phytotoxic effects of fluoride in leaf morpho-anatomy of Brachiaria brizantha (Hochst. Ex A. Rich.) Stapf and Brachiaria decumbens Stapf (Poaceae)). To assess the effects of fluoride on signal grass, plants of Brachiaria brizantha and B. decumbens were submitted to simulated fluoride fog $\left(10 \mu \mathrm{g} \mathrm{ml} l^{-1}\right)$. Leaf fragments from apparently healthy portions were colleted 24 hours after the last exposure and used for microscopic analysis. Roots, leaves and rhizomes were submitted to fluoride content quantification. The leaves presented small, sparse necroses. The accumulation of fluoride was observed on the leaves only. B. brizantha and B. decumbens presented, respectively, 4.4 and 5.2 times more fluoride than the control treatment. No difference was observed concerning the accumulation potential of both species. The main micromorphological alterations observed were injuries near the trichomes, therefore, suggesting that these are the preferential routes by which pollutants enter the plants. Visually healthy leaf portions of the two species showed microscopic damages before symptoms appeared, presenting turgidity loss in the bulliform cells of $B$. brizantha and in all tissues of $B$. decumbens. Micromorphometric alterations were observed only in $B$. decumbens, indicating higher sensibility to fluoride in comparison to $B$. brizantha. Further studies of long duration will be essential to determine the bioaccumulation potential of B. brizantha.

Key words: plant anatomy, signalgrass, necrosis

\section{Introdução}

O flúor, na condição de poluente atmosférico, apresenta grande importância em função de sua elevada fitotoxidade (Weinstein \& Davison 2003); próximo a fontes emissoras, sua concentração pode chegar a $12,87 \mu \mathrm{g} \mathrm{m}^{-3}$. Por ser cumulativo, o flúor pode ser repassado aos animais ao longo da cadeia alimentar e, por sua vez, ao homem, podendo causar doenças (Loganathan et al. 2004). A intoxicação por flúor pode ser crônica ou aguda. A crônica, mais comum, denomina-se fluorose, resultando em distúrbios na formação do esmalte dentário (DenBesten 1999). A aguda é rara e gera alterações musculares, gastrointestinais e nervosas (Lucioli et al. 2007). Dessa forma, plantas com elevadas concentrações de flúor são impróprias para a ingestão por herbívoros pois causam distúrbios metabólicos severos em animais (Sun \& Su 1985).

A principal via de entrada do flúor nas plantas é a folha, sendo também o órgão vegetal mais sujeito à ação deste poluente (Fornasiero 2001). Quando na forma gasosa, a entrada do flúor se dá através dos estômatos (Miller 1993), porém, em solução, este elemento pode ser absorvido por toda a superfície foliar. Segundo Sharma (1985), concentrações baixas de flúor, na faixa de $0,6 \mu \mathrm{g} \mathrm{m}^{-3}$, podem ser tóxicas a espécies sensíveis. Entretanto, algumas espécies denominadas bioacumuladoras são menos sensíveis a poluentes atmosféricos e capazes de acumular elementos tóxicos em seus tecidos (De Temmerman et al. 2004).

A sensibilidade das plantas ao flúor depende de fatores genéticos, edáficos, climáticos, dentre outros (Weinstein \& Davison 2003), sendo a seleção de espécies adaptadas ao clima tropical imprescindível em estudos de biomonitoramento (Chaves et al. 2002; Oliva \& Figueiredo 2005). Dentre as espécies vegetais, atualmente em estudo, destacam-se as gramíneas, por possuírem ampla distribuição geográfica nas regiões tropical e subtropical e elevadas taxas de crescimento, o que sugere a possibilidade do emprego de espécies sensíveis ou acumuladoras como indicadoras da presença de flúor no ambiente (Oliva \& Figueiredo 2005). No Brasil, Oliva \& Figueiredo (2005) avaliaram a sensibilidade de dez espécies de gramíneas tropicais, selecionando Panicum maximum cv. Colonião como espécie sensível que, posteriormente, foi utilizada por Divan Junior et al. (2007) como indicadora da presença de fluoreto nas adjacências de uma fonte emissora.

1 Universidade Federal de Viçosa, Departamento de Biologia Vegetal, Viçosa, MG, Brasil

2 Autor para correspondência: brunoufmg@ufmg.br 
A avaliação da sintomatologia, método mais utilizado para avaliar a sensibilidade de espécies vegetais a diversos fatores estressantes, freqüentemente requer validação adicional com interpretação microscópica (Vollenweider et al. 2003; Reig-Arminaña et al. 2004) sendo que, nos últimos anos, diversos autores têm utilizado a anatomia vegetal como ferramenta no estudo dos efeitos de poluentes em plantas (Fornasiero 2001; 2003; Chaves et al. 2002; Sant'AnnaSantos et al. 2006; 2007; Sant'Anna-Santos \& Azevedo 2007; Silva et al. 2005a; 2005b; 2006; Maranho et al. 2006; Alves et al. 2008; Pedroso \& Alves 2008).

$\mathrm{Na}$ bovinocultura, espécies do gênero Brachiaria são as mais utilizadas como forrageiras. Atualmente, o capimbraquiária é cultivado em 80 milhões de hectares, sendo $B$. brizantha e $B$. decumbens as espécies predominantes (Boddey et al. 2004). Considerando a ampla utilização de $B$. brizantha e $B$. decumbens como forrageiras na alimentação de bovinos, objetivou-se avaliar o potencial fitotóxico do flúor utilizando parâmetros morfoanatômicos e a capacidade de acumulação deste elemento, contribuindo com informações sobre a sensibilidade destas espécies ao poluente. Testaramse as hipóteses de que, ao serem expostas ao flúor, as plantas acumulariam o poluente em seus tecidos e responderiam com sintomas macroscópicos e injúrias microscópicas nas porções sem danos aparentes.

\section{Material e métodos}

Foram utilizadas as gramíneas Brachiaria brizantha (Hochst. ex A. Rich.) Stapf e B. decumbens Stapf, forrageiras amplamente empregadas como pastagem, selecionadas por apresentarem crescimento rápido, fator essencial para a caracterização das respostas ao tratamento com flúor (Silva et al. 2000).

O plantio foi realizado em substrato comercial Natura Tropical, composto de origem mineral enriquecido com húmus. Foram utilizados vasos plásticos com capacidade para $0,65 \mathrm{~L}$, acondicionados a $1 \mathrm{~m}$ do chão em bancada coberta por plástico transparente, a fim de evitar entrada de água.

Em cada vaso, dez gramas de sementes foram plantadas a lanço e cobertas por uma camada de $1 \mathrm{~cm}$ de substrato. Após a germinação, quando as plantas atingiram cerca de $10 \mathrm{~cm}$, realizou-se desbaste para uniformizar o estádio de desenvolvimento, deixando 15 plantas por vaso, seguindo protocolo proposto por Chaves et al. (2002).

$\mathrm{O}$ experimento foi composto por dois tratamentos e o delineamento experimental realizado em blocos ao acaso, com cinco vasos por tratamento. Dentre as 15 plantas de cada vaso, três foram marcadas para o acompanhamento do surgimento e evolução dos sintomas em resposta ao tratamento com flúor.

Ao atingirem o estádio de quatro folhas, as plantas foram expostas aos tratamentos, sendo submetidas a dez dias consecutivos de nevoeiros, segundo metodologia proposta por Silva et al. (2000). Durante cada simulação, as plantas foram expostas a $5,7 \mathrm{~mm}$ de nevoeiro. $\mathrm{O}$ tratamento com flúor foi preparado com $10 \mathrm{mg} \mathrm{L}^{-1}$ de $\mathrm{F}^{-}$na forma de $\mathrm{KF}$ ( $\mathrm{pH}$ 6,0), com o intuito de simular a concentração de flúor observada nas adjacências de áreas poluídas (Smith \& Hodge 1979). Com um pulverizador manual foram distribuídos, uniformemente, $200 \mathrm{ml}$ de solução sobre a superfície vegetal. No tratamento controle utilizou-se apenas água destilada ( $\mathrm{pH} \mathrm{6,0).}$

A coleta do material vegetal foi realizada $24 \mathrm{~h}$ após a última aplicação de nevoeiro simulado, amostrando-se folhas expandidas. As folhas foram digitalizadas em scanner e a área ocupada pelas manchas cloróticas e necróticas (porcentagem de área foliar com injúria) foi mensurada com auxílio do software Image Pro-Plus versão 4.1 para Windows ${ }^{\circledR}$. Utilizouse a seguinte escala proposta por Silva et al. (2000): levemente injuriada (com manchas necróticas e cloróticas esparsas), moderadamente injuriada (com 30 a 50\% da área foliar injuriada), muito injuriada (com 50 a 70\% da área foliar necrosada) e extremamente injuriada (com mais de $70 \%$ de área foliar necrosada).

Para a quantificação do conteúdo de flúor nos tecidos vegetais foram coletadas folhas, raízes e rizomas das plantas $(\mathrm{n}=5), 24 \mathrm{~h}$ após a última pulverização. As amostras foram previamente secas em estufa a $70^{\circ} \mathrm{C}$ e reduzidas, em moinho do tipo Wiley, a partículas com dimensões inferiores a $1 \mathrm{~mm}$. Alíquotas de $0,5 \mathrm{~g}$ de cada repetição foram submetidas à extração em ácido perclórico 0,1 M (Garcia-Ciudad et al. 1985), utilizando-se ajustador de força iônica (Larsen \& Widdowson 1971) para determinação do teor de flúor com eletrodo ín específico. As análises foram conduzidas em duplicata e repetidas duas vezes.

Para microscopia eletrônica de varredura foram retirados fragmentos da porção mediana de folhas expandidas $(\mathrm{n}=3)$. No tratamento com flúor foram feitas coletas de porções foliares sadias situadas próximas às injúrias. As amostras foram coletadas $24 \mathrm{~h}$ após o término das simulações, fixadas em solução de glutaraldeído $(2,5 \%)$ e paraformaldeído (4\%) em tampão cacodilato de sódio (pH 7,2) (Karnovsky 1965). Após desidratação em série etílica e secagem ao ponto crítico (equipamento modelo CPD 020, Bal-Tec, Balzers, Liechtenstein), os fragmentos foliares foram cobertos com ouro em metalizador (modelo FDU10, Bal-Tec, Balzers, Liechtenstein) e, em seguida, observados e documentados em microscópio eletrônico de varredura com câmera digital acoplada (modelo Leo 1430 VP, Zeiss, Cambridge, Inglaterra) do Núcleo de Microscopia e Microanálise da UFV.

Amostras foliares do tratamento controle e de porções foliares nãoinjuriadas do tratamento com flúor $(\mathrm{n}=5)$ foram fixadas em $\mathrm{FAA}_{50}$, por 48 horas, e estocadas em etanol $70 \%$. Realizou-se a desidratação do material em série etílica, seguida pela inclusão em metacrilato. Secções transversais com $3 \mu \mathrm{m}$ de espessura, obtidas em micrótomo rotativo de avanço automático (modelo RM2155, Leica Microsysems Inc., Deerfield, USA), foram coradas com azul de toluidina pH 4,0 (O’Brien \& McCully 1981) e montadas em resina sintética Permount. Para análise micromorfométrica foram mensuradas as áreas em secção transversal da epiderme das faces adaxial e abaxial, do mesofilo e do limbo. Foram realizadas 9 medidas/repetição/parâmetro, totalizando 36 registros por repetição com auxílio do software de análise de imagens Image Pro-Plus versão 4.1 para Windows ${ }^{\circledR}$. As observações e documentação fotográfica foram realizadas em fotomicroscópio (Olympus AX70TRF) com câmera digital acoplada.

As médias obtidas, referentes aos dados de área foliar injuriada, acúmulo de flúor nos tecidos e área foliar em secção transversal foram comparadas pelo Teste t com variâncias estimadas separadamente, em nível de $5 \%$ de significância.

\section{Resultados e discussão}

No tratamento controle, as folhas de ambas as espécies apresentaram coloração verde brilhante (Fig. 1A, 1D). Nas plantas expostas ao flúor, cloroses de forma e tamanho irregular e coloração verde-opaca foram observadas, principalmente, nas margens foliares, conforme observado por Chaves et al. (2002) em folhas de P. maximum e Chloris gayana expostas ao poluente. Como o flúor é um elemento eletronegativo, ele pode se ligar ao $\mathrm{Mg}^{2+}$ formando complexos responsáveis pelo surgimento de zonas sem coloração em algumas porções das folhas, devido à redução na biossíntese de clorofila (Fornasiero 2001). Com o decorrer do tempo de exposição, as cloroses evoluíram para necroses pequenas e esparsas localizadas nas margens e no ápice das folhas expostas ao flúor (Fig. 1B, 1C, 1E-F).

As lesões observadas surgiram cinco dias após o início da exposição ao flúor. Resultado semelhante foi observado por Oliva \& Figueiredo (2005), que ao estudar os efeitos do flúor $\left(15 \mu \mathrm{g} \mathrm{mL}^{-1}\right)$ em dez espécies de gramíneas verificaram que em $B$. decumbens os primeiros sintomas surgiram a partir do quarto dia de exposição ao poluente. 


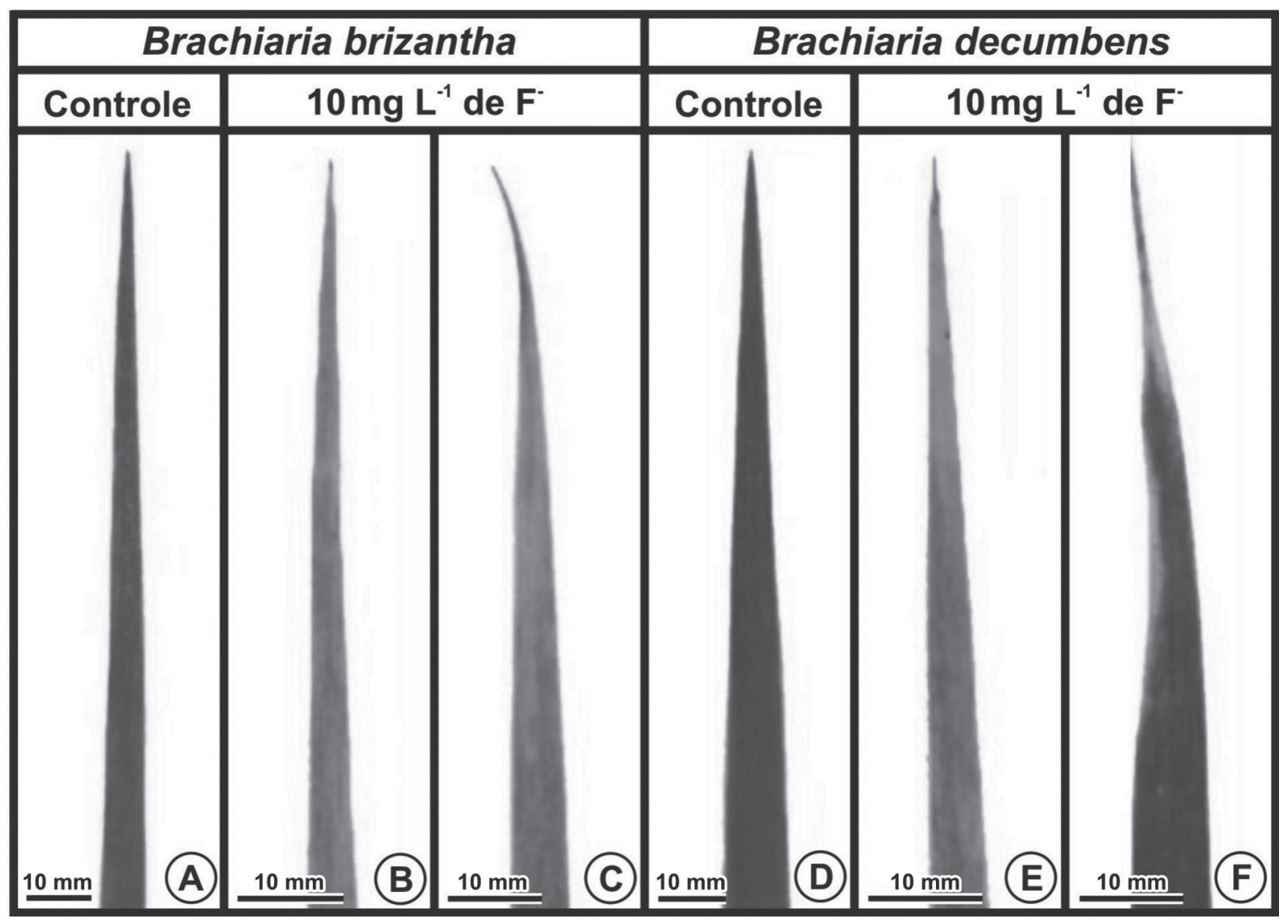

Figura 1. Sintomas da toxidez de flúor em folhas expandidas de Brachiaria brizantha (Hochst. ex A. Rich.) Stapf. e Brachiaria decumbens Stapf. A e D - Controle. $\mathrm{B}, \mathrm{C}, \mathrm{E}$ e F - Folhas cloróticas e com necroses apicais e marginais.

Ao final do experimento, observou-se uma pequena área foliar necrosada nas plantas de $B$. brizantha $(3,17 \pm 1,23 \%)$ e $B$. decumbens $(4,42 \pm 1,37 \%)$ expostas ao flúor, não tendo sido observada diferença significativa entre as duas espécies ( $\mathrm{p}>0,05)$. De acordo com a escala proposta por Silva et al. (2000), ambas as espécies de Brachiaria são classificadas como levemente injuriadas em resposta ao poluente, já que as lesões ocuparam uma área foliar inferior a 5\%.

As folhas jovens não apresentaram injúrias, como também observado por Fornasiero (2001), em H. perforatum. Entretanto, folhas jovens de P. maximum e C. gayana são as mais sensíveis ao flúor, como relatado por Chaves et al. (2002). Assim, a fitotoxidade deste poluente depende principalmente da espécie avaliada, do estádio de desenvolvimento foliar e da concentração do poluente.

As folhas expostas ao poluente acumularam flúor $(p<0,05)$ em concentrações 4,4 e 5,2 vezes maiores que nas plantas controle, em $B$. brizantha e $B$. decumbens, respectivamente (Tab. 1), não havendo diferença significativa entre as duas espécies. Nas raízes e rizomas não houve acúmulo significativo do poluente ( $\mathrm{p}>0,05)$, o que corrobora os dados de Ledbetter et al. (1960), que constataram que a folha é o principal sítio de acumulação de flúor nas plantas.
Ao microscópio eletrônico de varredura observou-se, nas folhas de ambas as espécies, a presença de corpos de sílica, células-guarda halteriformes e tricomas em forma de espinho, morfologicamente semelhantes a acúleos (Fig. 2A, 3A), sendo observados macropêlos somente em B. decumbens (Fig. 3B). Nas duas espécies, os principais danos foram observados nas adjacências dos tricomas. Em B. brizantha, o flúor ocasionou a ruptura da cutícula na proximidade dos pêlos acúleos, promovendo o rompimento da parede do pêlo ou até mesmo seu completo destacamento do tecido epidérmico, levando à exposição da porção interna da célula (Fig. 2B-E). Já em $B$. decumbens, as lesões causadas pelo flúor estavam associadas aos macropêlos, que tiveram a cutícula rompida, levando à perda da célula apical do tricoma (Fig. 3C-E). Para Pushnik \& Miller (1990), o flúor não se distribui uniformemente na folha, tendendo a se acumular nas áreas próximas ao ponto de entrada, como estômatos e/ou tricomas, onde ocorrem os maiores danos. Em Panicum maximum e Chloris gayana, os dados obtidos por Chaves et al. (2002) indicam a base dos tricomas como a via preferencial de entrada do flúor, em solução, nas folhas. Nas folhas expostas ao poluente, em ambas as espécies, ocorreu infestação por hifas nas proximidades de áreas com ceras epicuticulares 

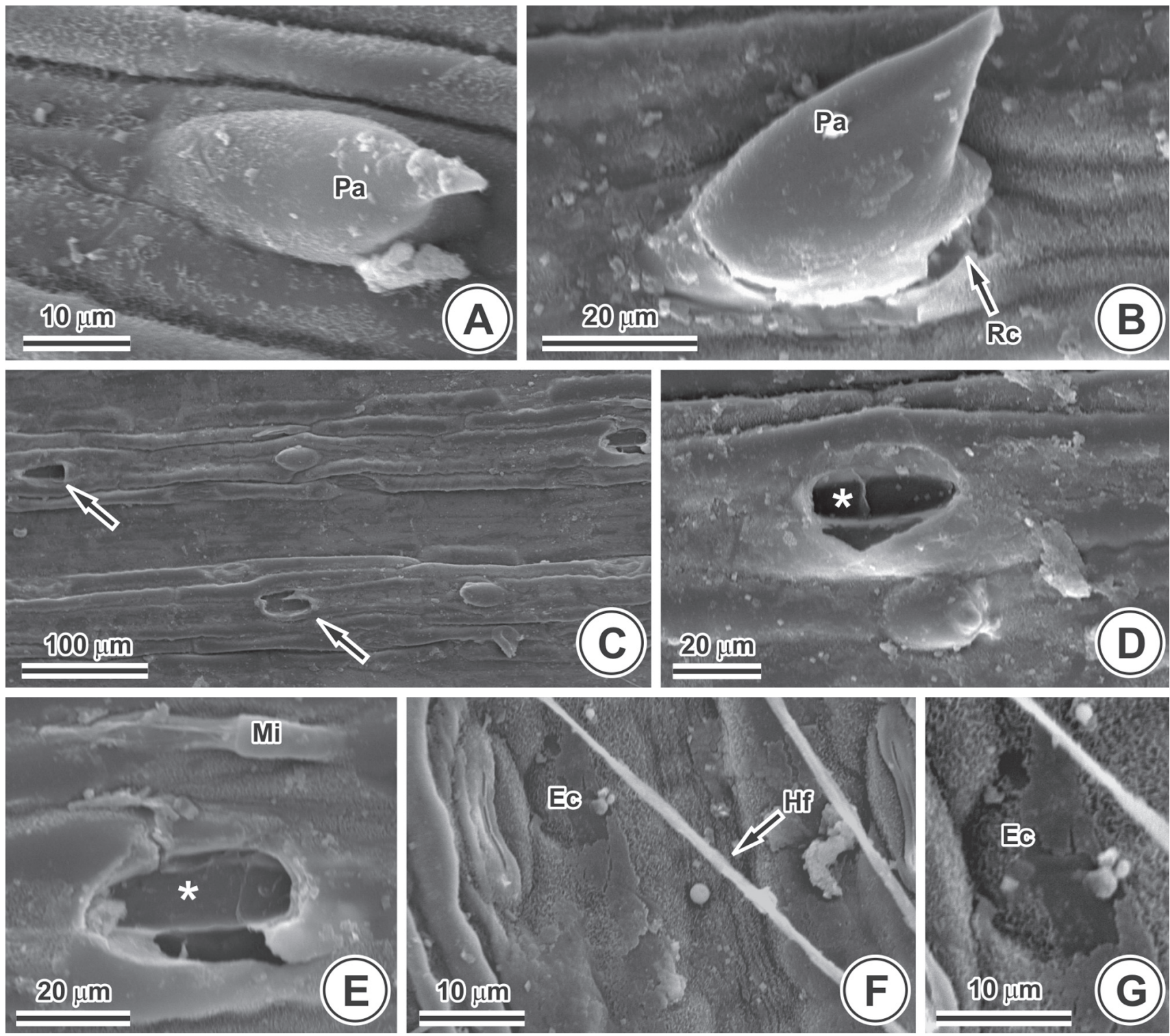

Figura 2. Micromorfologia foliar de Brachiaria brizantha (Hochst. ex A. Rich.) Stapf. A - Controle: pêlo acúleo (Pa). B-G - Flúor. B - Ruptura da cutícula (Rc). C Ruptura dos pêlos acúleos (setas). D-E - Cicatrizes da queda de pêlo (*). F-G - Erosão da cera epicuticular (Ec) e hifas (Hf). Mi = micropêlo.

Tabela 1. Concentração de fluoreto nas raízes e rizomas de Brachiaria brizantha (Hochst. ex A. Rich.) Stapf. e Brachiaria decumbens Stapf.

\begin{tabular}{cccc}
\hline Espécie & Órgão & Controle $\left(\mu \mathrm{g} \mathrm{g}^{-1}\right)$ & Flúor $\left(\mu \mathrm{g} \mathrm{g}^{-1}\right)$ \\
\hline B. brizantha & Folha & $1,24 \pm 0,12 \mathrm{Ab}$ & $5,44 \pm 0,46 \mathrm{Aa}$ \\
B. decumbens & & $1,12 \pm 0,04 \mathrm{Ab}$ & $5,78 \pm 0,62 \mathrm{Aa}$ \\
B. brizantha & Raiz & $0,02 \pm 0,01 \mathrm{Aa}$ & $0,01 \pm 0,00 \mathrm{Aa}$ \\
B. decumbens & & $0,02 \pm 0,01 \mathrm{Aa}$ & $0,01 \pm 0,00 \mathrm{Aa}$ \\
B. brizantha & Rizoma & $0,06 \pm 0,02 \mathrm{Ba}$ & $0,05 \pm 0,03 \mathrm{Ba}$ \\
B. decumbens & & $0,14 \pm 0,01 \mathrm{Aa}$ & $0,13 \pm 0,04 \mathrm{Aa}$ \\
\hline
\end{tabular}

Letras iguais na coluna, dentro de cada fração, e minúsculas na linha não diferem significativamente ( $>00,05)$, segundo o teste $t$ student.

erodidas (Fig. 2F-G, 3C). A remoção da cera epicuticular e dos tricomas, bem como a ruptura da cutícula, propiciam o maior umedecimento da superfície foliar, facilitando a proliferação de fungos (Sant'Anna-Santos et al. 2007).
No tratamento controle observou-se que as duas espécies apresentam caracteres anatômicos semelhantes (Fig. 4A, 5A). A partir da análise anatômica observou-se que, em resposta ao flúor, porções foliares visualmente sadias de 


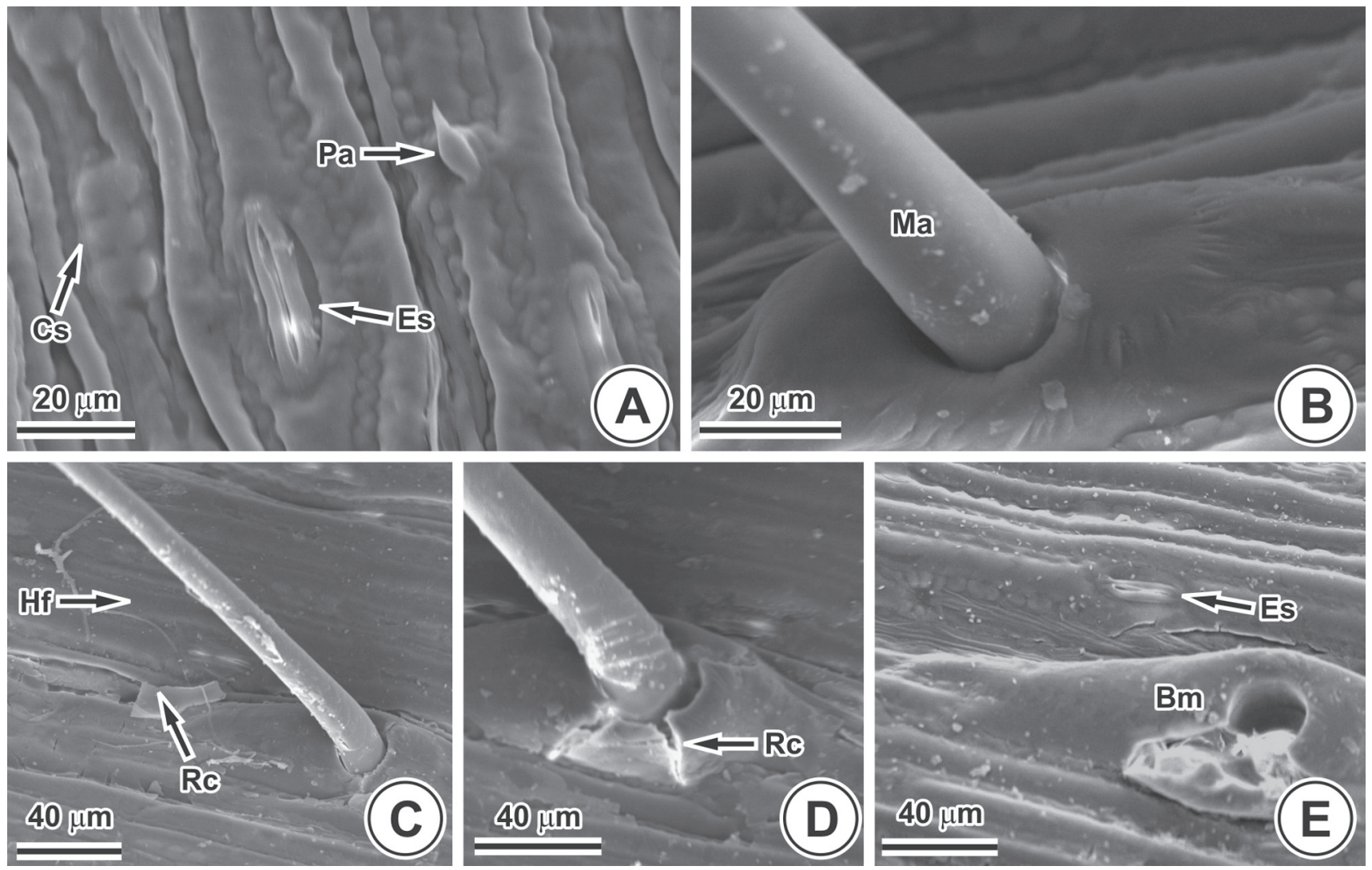

Figura 3. Micromorfologia foliar de Brachiaria decumbens Stapf. A-B - Controle. A - Pêlos acúleos (Pa) e corpos de sílica (Cs). B - Macropêlo (Ma). C-E - Flúor. C - Hifa (Hi) e ruptura da cutícula (Rc). D e E - Ruptura da cutícula e da base do macropêlo (Bm). Es = estômato.

ambas as espécies de Brachiaria apresentam danos microscópicos antes do surgimento de sintomas, conforme relatado na literatura (Sant'Anna-Santos et al. 2007). Houve perda da turgidez das células buliformes em $B$. brizantha (Fig. 4B) e de todos os tecidos em $B$. decumbens, observando-se desde pequenas sinuosidades na parede celular até o completo achatamento das células (Fig. 5B). Em B. brizantha não foram detectadas alterações significativas $(\mathrm{p}>0,05)$ nos caracteres micromorfométricos avaliados (Tab. 2). Já em $B$. decumbens, o flúor provocou alterações $(\mathrm{p}<0,05)$ em todos os caracteres foliares mensurados (Tab. 2). Nesta espécie, verificou-se redução de $34,0 \%$ da área do limbo, em secção transversal, nas plantas expostas ao poluente, em relação ao controle. A epiderme da face adaxial foi o tecido mais afetado pelo flúor, com diminuição de $44,8 \%$. Os dados micromorfométricos supracitados confirmam uma maior sensibilidade de $B$. decumbens ao flúor, em comparação com $B$. brizantha. As alterações anatômicas têm sido freqüentemente utilizadas como subsídio para comparação da susceptibilidade entre espécies (Sant'Anna-Santos et al. 2006) e até mesmo cultivares diferentes (Tuffi Santos et al. 2008) em resposta a agentes estressantes.

As duas espécies de braquiária estudadas apresentam taxas de acúmulo de fluoreto e sintomatologia semelhantes

Tabela 2. Área em secção transversal dos tecidos constituintes das folhas de Brachiaria brizantha (Hochst. ex A. Rich.) Stapf. e Brachiaria decumbens Stapf.

\begin{tabular}{|c|c|c|c|}
\hline Espécie & Região & Controle $\left(\mu \mathrm{m}^{2}\right)$ & Flúor $\left(\mu \mathrm{m}^{2}\right)$ \\
\hline $\begin{array}{l}\text { B. brizantha } \\
\text { B. decumbens }\end{array}$ & Epiderme da face adaxial & $\begin{array}{l}18.756 \pm 2.395 \mathrm{Aa} \\
19.344 \pm 1.103 \mathrm{Aa}\end{array}$ & $\begin{array}{l}16.760 \pm 4.513 \mathrm{Aa} \\
10.530 \pm 2.082 \mathrm{Ab}\end{array}$ \\
\hline $\begin{array}{l}\text { B. brizantha } \\
\text { B. decumbens }\end{array}$ & Mesofilo & $\begin{array}{l}70.595 \pm 8.858 \mathrm{Aa} \\
74.279 \pm 6.980 \mathrm{Aa}\end{array}$ & $\begin{array}{c}65.914 \pm 12.405 \mathrm{Aa} \\
50.674 \pm 9.230 \mathrm{Ab}\end{array}$ \\
\hline $\begin{array}{l}\text { B. brizantha } \\
\text { B. decumbens }\end{array}$ & Epiderme da face abaxial & $\begin{array}{l}9.580 \pm 935 \mathrm{Aa} \\
8.914 \pm 450 \mathrm{Aa}\end{array}$ & $\begin{array}{c}8.880 \pm 1.133 \mathrm{Aa} \\
6.192 \pm 894 \mathrm{Bb}\end{array}$ \\
\hline $\begin{array}{l}\text { B. brizantha } \\
\text { B. decumbens }\end{array}$ & Limbo & $\begin{array}{l}98.932 \pm 10.807 \mathrm{Aa} \\
102.538 \pm 8.198 \mathrm{Aa}\end{array}$ & $\begin{array}{l}90.693 \pm 14.147 \mathrm{Aa} \\
67.397 \pm 12.054 \mathrm{Bb}\end{array}$ \\
\hline
\end{tabular}

Letras iguais na coluna, dentro de cada fração, e minúsculas na linha não diferem significativamente ( $\mathrm{p}>0,05)$, segundo o teste $\mathrm{t}$ student. 


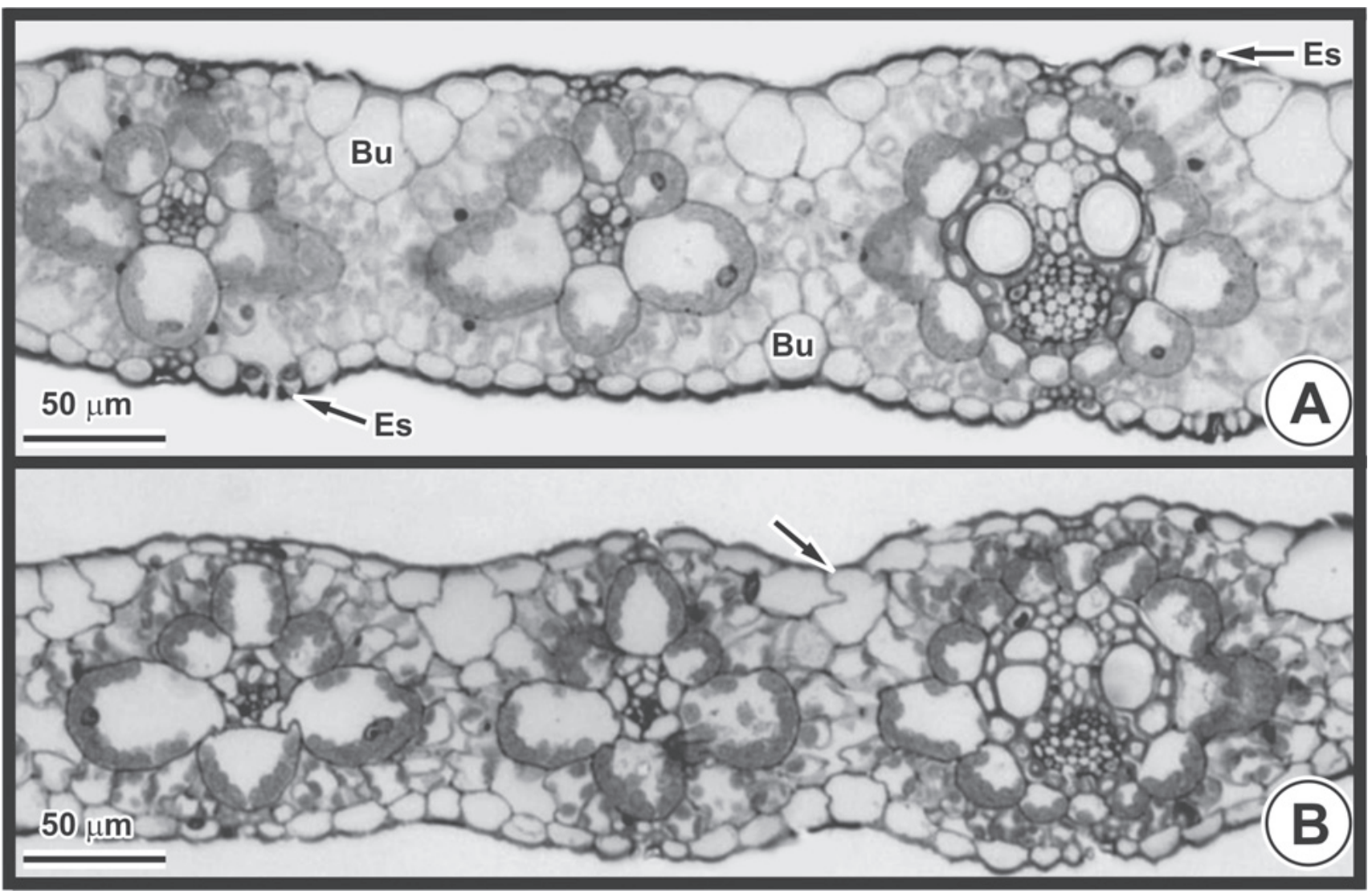

Figura 4. Anatomia foliar de Brachiaria brizantha (Hochst. ex A. Rich.) Stapf. (microscopia de luz - secção transversal). A - Controle: estômatos (Es) e células buliformes $(\mathrm{Bu})$ em ambas as faces. B - Flúor: células buliformes com forma alterada (seta).

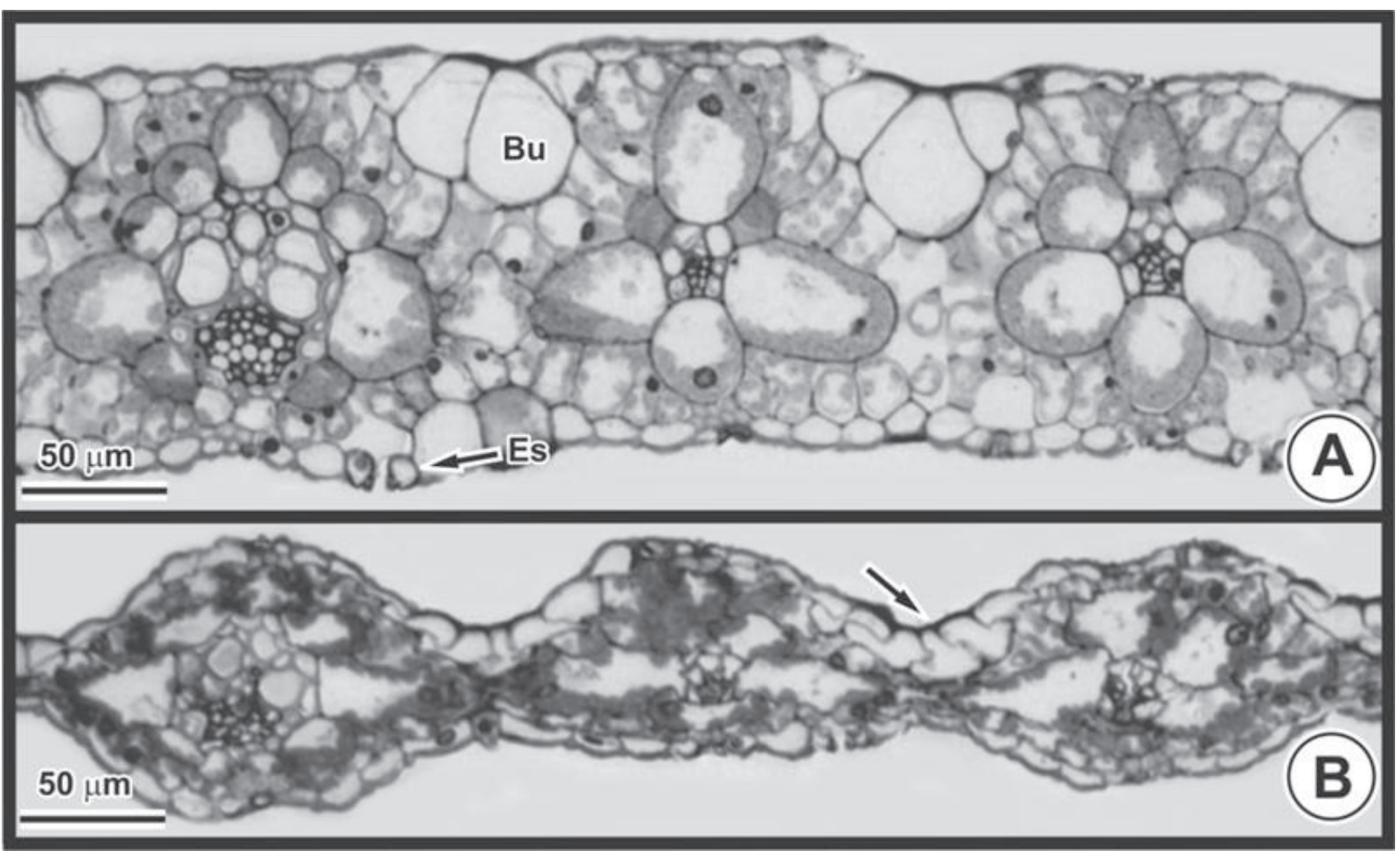

Figura 5. Anatomia foliar de B. decumbens Stapf. (microscopia de luz - secção transversal). A - Controle: células buliformes (Bu) na face adaxial. B - Flúor: células epidérmicas e do mesofilo com forma alterada (seta) e redução na espessura da folha. Estômato $=(E s)$. 
quando expostas ao poluente. Os danos micromorfológicos foram evidentes e similares em ambas as espécies e sugerem que os tricomas sejam vias preferenciais de penetração do flúor. Apesar das alterações micromorfológicas observadas nas duas espécies estudadas, $B$. decumbens é mais sensível que $B$. brizantha devido às alterações micromorfométricas, que indicam a ocorrência de danos em nível celular, antes mesmo do aparecimento dos sintomas na região analisada. Experimentos de longa duração serão essenciais para determinar o potencial bioacumulador de B. brizantha.

\section{Agradecimentos}

Os autores agradecem ao Núcleo de Microscopia e Microanálise da UFV, a Vânia Maria Valente, pelo auxílio em parte dos procedimentos laboratoriais e a Daniela Chaves Resende, pela ajuda prestada para a realização das análises estatísticas.

\section{Referências bibliográficas}

Alves, E.S.; Tresmondi, F. \& Longui, E.L. 2008. Análise estrutural de folhas de Eugenia uniflora L. (Myrtaceae) coletadas em ambientes rural e urbano, SP, Brasil. Acta Botanica Brasilica 22: 241-248.

Boddey, R.M.; Macedo, R.; Tarre, R.M.; Ferreira, E.; Oliveira, O.C.; Rezende, C.P.; Cantarutti, R.B.; Pereira, J.M.; Alves, B.J.R. \& Urquiaga, S. 2004. Nitrogen cycling in Brachiaria pastures: the key to understending the process of pasture decline. Agriculture, Ecosystems \& Environment 103: 389-403.

Chaves, A.L.F.; Silva, E.A.M.; Azevedo, A.A.; Cano, M.A.O. \& Matsuoka, K. 2002. Ação do flúor dissolvido em chuva simulada sobre a estrutura foliar de Panicum maximum Jacq. (colonião) e Chloris gayana Kunth. (capim-rhodes) - Poaceae. Acta Botanica Brasílica 16: 395-406.

De Temmerman, L.; Bell, J.N.B.; Garrec, J.P.; Klumpp, A.; Krause, G.H.M. \& Tonneijck, A.E.G. 2004. Biomonitoring of air pollutants with plants - considerations for the future. In: A. Klumpp; W. Ansel \& G. Klumpp (eds.): Urban air pollution, bioindication and environmental awareness. Göttingen, Cuvillier Verlag.

Denbesten, P.K. 1999. Biological mechanisms of dental fluorosis relevant to the use of fluoride supplements. Community Dentistry and Oral Epidemiology 27: 41-47.

Divan Junior, A.M.; Oliva, M.A.; Martinez, C.A. \& Cambraia, J. 2007. Effects of fluoride emissions on two tropical grasses: Chloris gayana and Panicum maximum cv. Colonião. Ecotoxicology and Environmental Safety 67: 247-253.

Fornasiero, R.B. 2001. Phytotoxic effects of fluorides. Plant Science 161: 979-985.

Fornasiero, R.B. 2003. Fluorides effects on Hypericum perforatum plants: first field observations. Plant Science 165: 507-513.

Garcia-Ciudad, A.; Garcia-Criado, B. \& Emetrio, C.P. 1985. Dertemination of fluoride in plant samples by a potentiometric method and nearinfrared reflectance spectroscopy. Communications in Soil Science and Plant Analysis 16: 1107-1122.

Karnovsky, M.J. 1965. A formaldehyde-glutaraldehyde fixative of high osmolarity for use in electron microscopy. Journal of Cell Biology 27: $137-138$

Larsen, S. \& Widdwson, A.E. 1971. Soil Fluoride. Journal of Soil Science 22: $210-221$

Ledbetter, M.C; Mavrodineanu, R. \& Weiss, A.J. 1960. Distribution studies of radioactive fluoride-18 and stable fluoride-19 in tomato plants. Contribution of the Boyce Thompson Institute 20: 331-348.

Loganathan, P.; Hedley, M.J.; Bretherton, M.R. \& Rowarth, J.S. 2004. Accounting for particle movement when assessing the dissolution of slow release fertilizers in field soils. Nutrient Cycling in Agroecosystems 70: 77-84.
Lucioli, J.; Furlan, F.H.; Mezaroba, S.; Raymundo, D.L.; Bechtold, S.L.; Traverso, S.D. \& Gava, A. 2007. Intoxicação aguda por fluosilicato de sódio em bovinos no Estado de Santa Catarina. Pesquisa Veterinária Brasileira 27: 49-52.

Maranho, L.T.; Galvão, F.; Preussler, K.H.; Muñiz, G.I.B. \& Kuniyoshi, Y.S. 2006. Efeitos da poluição por petróleo na estrutura da folha de Podocarpus lambertii Klotzsch ex Endl., Podocarpaceae. Acta Botanica Brasilica 20: 501-750.

Miller, G.W. 1993. The effect of fluoride on higher plants: with especial emphasis on early physiological and biochemical disorders. Fluoride 26: 3-22.

O'Brien, T.P. \& McCully, M.E. 1981. The study of plant structure principles and select methods. Melbourne, Termarcarphi Pty.

Oliva, M.A. \& Figueiredo, J.G. 2005. Gramíneas bioindicadoras de flúor em regiões tropicais. Revista Brasileira de Botânica 28: 389-397.

Pedroso, A.N.V. \& Alves, E.S. 2008. Anatomia foliar comparativa das cultivares de Nicotiana tabacum L. (Solanaceae) sensível e tolerante ao ozônio. Acta Botanica Brasilica 22: 21-28.

Pushnik, J.C. \& Miller, G.W. 1990. The influences of elevated environmental fluoride on the physiology and metabolism of higher plants. Fluoride 23: 5-19.

Reig-Arminaña, J.; Calatayud, V.; Cervero, J.; Garcia-Breijo, F.J.; Ibars, A. \& Sanz, M.J. 2004. Effects of ozone on the foliar histology of the mastic plant (Pistacia lentiscus L.). Environmental Pollution 132: 321-331.

Sant'Anna-Santos, B.F. \& Azevedo, A.A. 2007. Aspectos morfoanatômicos da fitotoxidez do flúor em duas espécies arbóreas tropicais. Revista Brasileira de Biociências 5: 48-50.

Sant'Anna-Santos, B.F.; Silva, C.S.; Azevedo, A.A.; Araújo, J.M.; Alves, E.F.; Silva, E.A.M. \& Aguiar, R. 2006. Effects of simulated acid rain on the foliar micromorphology and anatomy of tree tropical species. Environmental and Experimental Botany 58: 158-168.

Sant'Anna-Santos, B.F.; Duque-Brasil, R.; Azevedo, A.A.; Silveira, A.S.; Araújo, J.M. \& Aguiar, R. 2007. Utilização de parâmetros morfoanatômicos na análise da fitotoxidez do flúor em folhas de Magnolia ovata (A. St.-Hil.) Spreng. (Magnoliaceae). Revista Árvore 31: 761-771.

Sharma, H.C. 1985. Effect of hidrogen fluoride fumigation in Triticum aestivum, Brassica juncea and Phaseolus aureus plants. Fluoride 18: 5-22.

Silva, L.C.; Azevedo, A.A.; Silva, E.A. \& Oliva, M.A. 2000. Flúor em chuva simulada: sintomatologia e efeitos sobre a estrutura foliar e o crescimento de plantas arbóreas. Revista Brasileira de Botânica 23: 385-393.

Silva, L.C.; Azevedo, A.A.; Silva, E.A.M. \& Oliva, M.A. 2005a. Effects of simulated acid rain on the growth of five Brazilian tree species and anatomy of the most sensitive species (Joannesia princeps). Australian Journal of Botany 53: 789-796.

Silva, L.C.; Oliva, M.A.; Azevedo, A.A.; Araújo, J.M. \& Aguiar, R.M. 2005b. Micromorphological and anatomical alterations caused by simulated acid rain in restinga plants: Eugenia uniflora and Clusia hilariana. Water, Air and Soil Pollution 168: 129-143.

Silva, L.C.; Oliva, M.A.; Azevedo, A.A. \& Araújo, J.M. 2006. Responses of restinga plant species to pollution from an iron pelletization factory. Water Air and Soil Pollution 175: 241-256.

Smith, F.A. \& Hodge, H.C. 1979. Airbone fluorides and man: Part I. Critical Review of Environment Control 8: 293-372.

Sun, E.G. \& Su, H.J. 1985. Fluoride injury to rice plants caused by air pollution emitted from ceramic brick factories. Environmental Pollution 37: 335-342.

Tuffi Santos, L.D.; Sant'Anna-Santos, B.F.; Meira, R.M.S.A.; Tiburcio, R.A.S.; Ferreira, F.A.; Melo, C.A.D. \& Silva, E.F.S. 2008. Danos visuais e anatômicos causados pelo glyphosate em folhas de Eucalyptus grandis. Planta Daninha 26: 9-16.

Vollenweider, P.; Ottiger, M. \& Günthardt-Goerg, M.S. 2003. Validation of leaf ozone symptoms in natural vegetation using microscopical methods. Environmental Pollution 124: 101-118.

Weinstein, L.H. \& Davison, A.W. 2003. Native plant species suitable as bioindicators and biomonitors for airbone fluoride. Environmental Pollution 125: 3-11. 